\title{
Acute insulin resistance in ST-segment elevation myocardial infarction in non-diabetic patients is associated with incomplete myocardial reperfusion and impaired coronary microcirculatory function
}

Danijela Trifunovic ${ }^{1,2^{*}}$, Sanja Stankovic ${ }^{3}$, Dragana Sobic-Saranovic ${ }^{2,4}$, Jelena Marinkovic ${ }^{5}$, Marija Petrovic ${ }^{1}$, Dejan Orlic ${ }^{1,2}$, Branko Beleslin 1,2, Marko Banovic ${ }^{1,2}$, Bosiljka Vujisic-Tesic ${ }^{1,2}$, Milan Petrovic ${ }^{1,2}$, Ivana Nedeljkovic ${ }^{1,2}$, Jelena Stepanovic ${ }^{1,2}$, Ana Djordjevic-Dikic ${ }^{1,2}$, Milorad Tesic ${ }^{1}$, Nina Djukanovic ${ }^{1}$, Olga Petrovic ${ }^{1}$, Olga Vasovic ${ }^{6}$,Emilija Nestorovic ${ }^{1}$, Jelena Kostic ${ }^{1}$, Arsen Ristic ${ }^{1,2}$ and Miodrag Ostojic ${ }^{6,7}$

\begin{abstract}
Background: Insulin resistance (IR) assessed by the Homeostatic Model Assessment (HOMA) index in the acute phase of myocardial infarction in non-diabetic patients was recently established as an independent predictor of intrahospital mortality. In this study we postulated that acute IR is a dynamic phenomenon associated with the development of myocardial and microvascular injury and larger final infarct size in patients with ST-segment elevation myocardial infarction (STEMI) treated by primary percutaneous coronary intervention (pPCI).
\end{abstract}

Methods: In 104 consecutive patients with the first anterior STEMI without diabetes, the HOMA index was determined on the $2^{\text {nd }}$ and $7^{\text {th }}$ day after $\mathrm{pPCl}$. Worst-lead residual ST-segment elevation (ST-E) on postprocedural ECG, coronary flow reserve (CFR) determined by transthoracic Doppler echocardiography on the $2^{\text {nd }}$ day after $\mathrm{pPCl}$ and fixed perfusion defect on single-photon emission computed tomography myocardial perfusion imaging (SPECT-MPI) determined six weeks after PPCI were analyzed according to HOMA indices.

Results: IR was present in $55 \%$ and $58 \%$ of patients on day 2 and day 7, respectively. Incomplete post-procedural ST-E resolution was more frequent in patients with IR compared to patients without IR, both on day $2(p=0.001)$ and day $7(p<0.001)$. The HOMA index on day 7 correlated with SPECT-MPI perfusion defect $(r=0.331)$, whereas both HOMA indices correlated well with CFR $(r=-0.331$ to -0.386$)$ ( $p<0.01$ for all). In multivariable backward logistic regression analysis adjusted for significant univariate predictors and potential confounding variables, IR on day 2 was an independent predictor of residual ST-E $\geq 2 \mathrm{~mm}$ (OR 11.70, 95\% Cl 2.46-55.51, $\mathrm{p}=0.002)$ and CFR $<2$ (OR=5.98, 95\% Cl 1.88-19.03, $p=0.002$ ), whereas IR on day 7 was an independent predictor of SPECT-MPI perfusion defect $>20 \%$ (OR 11.37, 95\% Cl 1.34-96.21, $\mathrm{p}=0.026$ ).

Conclusion: IR assessed by the HOMA index during the acute phase of the first anterior STEMI in patients without diabetes treated by $\mathrm{pPCl}$ is independently associated with poorer myocardial reperfusion, impaired coronary microcirculatory function and potentially with larger final infarct size.

Keywords: Insulin resistance, Acute myocardial infarction, ST-E resolution, Coronary microcirculation, Infarct size

\footnotetext{
* Correspondence: danijelatrif@gmail.com

'Department of Cardiology, Clinical Centre of Serbia, UI. Koste Todorovica 8,

11000 Belgrade, Serbia

${ }^{2}$ School of Medicine, University of Belgrade, Belgrade, Serbia

Full list of author information is available at the end of the article
} 


\section{Background}

Full myocardial reperfusion with restoration of coronary microcirculatory function (CMF) is a therapeutic goal in ST-segment elevation myocardial infarction (STEMI) [1]. Despite successful primary percutaneous intervention (pPCI) it is not achieved in $30 \%$ to $50 \%$ of patients $[2,3]$. The reasons are complex, and include also several metabolic issues [3].

Insulin resistance (IR) as a part of metabolic syndrome is an important risk factor for the development of cardiac and vascular impairments $[4,5]$ and carries ominous prognosis in the setting of acute myocardial infarction [6]. As a part of metabolic syndrome IR is associated with myocardial and microvascular injury after STEMI in clinical $[7,8]$ and experimental studies [9]. Data connecting metabolic syndrome to the final infarct size are less clear [10-12]. However, emerging evidences support direct proatherogenic effects of IR [13-15], as well as its direct adverse effects on myocardial contractility [16]. As phenomenon per se, independent of other components of metabolic syndrome, IR was related to ischemic myocardial injury after elective PCI [17].

Recently, IR in the early phase of acute coronary syndrome in non-diabetic patients, assessed by the homeostatic model assessment (HOMA) index, was established as an independent predictor of in-hospital mortality [18-21]. This "acute" IR is a part of the acute glycometabolic response to stress, can be transient and can occur even in patients without chronic glycometabolic derangements [22]. Data regarding the relationships between acute IR and CMF after pPCI are scarce. Acute IR comprises acute hyperglycemia and/or acute hyperinsulinemia [23]. Hyperglycemia in STEMI patients has direct acute negative cardiovascular effects contributing to incomplete myocardial reperfusion and CMF impairment [24-28]. The prognostic relevance of hyperinsulinemia in STEMI patients $[29,30]$ and its relationship with coronary flow [31] are less well evaluated and acknowledged.

We postulate that IR can occur in the early post pPCI period as a dynamic phenomenon even in non-diabetic patients, and be related to the development of microvascular and myocardial injury and final infarct size, independently of other variables. Accordingly, we have evaluated time dependent changes of IR in relation to myocardial reperfusion, CMF and final infarct size in non-diabetic STEMI patients treated by pPCI. We have defined coronary flow reserve (CFR), a marker of CMF, as a primary end-point. The residual ST-segment elevation (ST-E) and final infarct size were secondary endpoints.

The HOMA index is a simple and inexpensive marker of IR primary used in chronic states. It was recently validated against euglycemic hyperinsulinemic clamp in STEMI patients as feasible for assessing IR during myocardial infarction [32] and therefore used in the current study.

\section{Methods}

\section{Patient population}

The inclusion criteria for this prospective, single center, observational study included recanalization of left anterior descending artery (LAD) with visually assessed residual stenosis $<30 \%$. The STEMI was defined and treated according to ESC guidelines [1]. Diabetes mellitus was defined according to the American Diabetes Association criteria [33] and patients without previously known diabetes but with $\mathrm{HbA} 1 \mathrm{c}>6.5 \%$ on admission were not included. The exclusion criteria also included: (1) inability or refusal to obtain written informed consent; (2) inability to perform echocardiography examination with coronary flow reserve (CFR) measurements with adenosine due to hemodynamic instability, technically poor acoustic window precluding satisfactory imaging of the left ventricle (LV) or LAD flow by Doppler, or states known as contraindications for adenosine administration (chronic obstructive pulmonary disease, $2^{\text {nd }}$ or $3^{\text {rd }}$ AV blocks); (3) significant valvular disease, (4) temporary or permanent pacemaker and left bundle branch block precluding ECG analysis, (5) acute or chronic infection, (6) a history of autoimmune, malignant, liver, kidney or thyroid diseases. The Ethical committee of our hospital approved the study protocol. The patients were asked to participate in the study and to sign informed consent on admission to the hospital, before pPCI. Anthropometric parameters including weight and height were measured for all patients, and their body mass index (BMI) was calculated as ratio of weight to height squared. Hypertension was defined as systolic blood pressure $\geq$ $140 \mathrm{mmHg}$, a diastolic blood pressure $\geq 90 \mathrm{mmHg}$, or use of antihypertensive treatment. Patients were considered smokers if they smoked $\geq 1$ cigarette/day at the time of admission or in the preceding 12 months. The Killip class, depending on the clinical manifestation of cardiac failure, was assessed on admission (Killip 1, no heart failure; Killip 2, S3 and/or basal lung crepitations; Killip 3, acute pulmonary edema; Killip 4, cardiac shock).

\section{Blood sampling and biochemical analysis}

When a diagnosis of STEMI was established and a decision to perform pPCI was made, blood samples were obtained from a peripheral vein before starting intervention and after admission to the intensive coronary care unit every $6 \mathrm{~h}$ during the first $48 \mathrm{~h}$ and every $12 \mathrm{~h}$ during the rest of the stay in the intensive coronary care unit. Blood samples for troponin I (TnI), MB fraction of creatine kinase (CK-MB), $\mathrm{N}$-terminal pro-brain natriuretic peptide (NT-proBNP), and high-sensitive C-reactive protein (hs-CRP) determination were allowed to coagulate at room temperature for $30 \mathrm{~min}$, and then centrifuged at $4000 \mathrm{rpm}$ for $10 \mathrm{~min}$ to obtain serum samples. Serum TnI and CK-MB were measured by chemiluminescent microparticle immunoassay (CMIA) on Architect i2000 System. The serum levels of 
NT-proBNP were measured by a Roche Cobas 6000 automated analyzer (Roche Diagnostics, Mannheim, Germany). The serum hs-CRP concentrations were measured by means of the immunoturbidimetric test (Olympus Life and Material Science Europe $\mathrm{GmbH}$, Ireland) on an Olympus AU 400 analyzer. The lowest detectable level was $0.02 \mathrm{mg} / \mathrm{L}$. Serum insulin was measured using a chemiluminescent microparticle immunoassay on an Architect i2000SR instrument (Abbott Diagnostics, Wiesbaden, Germany). According to the manufacturer's package insert, Architect Insulin assay has a measurement range of $1-300 \mu \mathrm{U} / \mathrm{mL}$ with analytical sensitivity $\leq 1.0 \mu \mathrm{U} / \mathrm{mL}$. Other biochemical and hematologic measurements involved the use of standard assays. The peak values for CK-MB, Tn I, NT-proBNP and hs-CRP were considered for further analysis and for other biochemical parameters $2^{\text {nd }}$ day values were used for analysis, because CFR was measured on the $2^{\text {nd }}$ day. The HOMA was calculated on the $2^{\text {nd }}$ and $7^{\text {th }}$ day according to the following formula: (fasting insulin $[\mu \mathrm{U} / \mathrm{mL}] \times$ fasting glucose $[\mathrm{mmol} / \mathrm{L}]) / 22.5$. Patients whose values exceeded the sex-specific 75 th percentile (i.e., 1.80 for women and 2.12 for men) were considered to have HOMA-IR according to guidelines proposed by the European Group for the study of Insulin Resistance (EGIR) [34]. The estimated glomerular filtration rate (eGFR) was calculated using abbreviated Modification of Diet in Renal Disease study formula [35].

\section{Primary $\mathrm{PCl}$}

PCI was performed within $12 \mathrm{~h}$ from the onset of chest pain by experienced interventionists. Coronary angiography was performed as quickly as possible. Collateral flow from the patent vessels to the infarct-related artery was graded using the classification developed by Rentrop [36]. In all patients, a stent was successfully implanted in the LAD. Angiographic Thrombolysis In Myocardial Infarction (TIMI) flow grade was evaluated as described previously [37]. Slow/no-reflow was defined as TIMI $\leq 2$ after PCI. All patients and their angiograms were graded according to the number of diseased coronary arteries. A coronary artery was considered diseased if there was any obstructive lesion $\geq 70 \%$ in diameter in that artery or one of its major branches (diameter $\geq 2.5 \mathrm{~mm}$ ). Medication used in the acute phase included loading a dose of clopidogrel $600 \mathrm{mg}$ and aspirin $300 \mathrm{mg}$ and intravenous bolus of heparin before $\mathrm{pPCI}$, followed by dual antiplatelet therapy (clopidogrel or ticlopidine and aspirin) and statins in all patients. ACE-I/ARB, beta blockers, diuretics, digitalis and calcium antagonist were used in $82 \%, 96 \%, 52 \%, 9 \%, 9 \%$, respectively. Glicoprotein IIb/IIIa inhibitor, thrombectomy and intracoronary vasodilatators were administered at the discretion of the interventional cardiologist. In the current study $24 \%$ of patients had thiazide diuretics in therapy and $98 \%$ of patients had statins from the $3^{\text {rd }}$ day after pPCI.
None of the patients included in the current study reached the glycaemic threshold of $11 \mathrm{mmol} / \mathrm{l}$ to get insulin.

\section{Outcome variables}

CMF estimated by coronary flow reserve (CFR) was defined as a primary endpoint. Myocardial perfusion, assessed by the residual ST-E, and infarct size, evaluated by the fixed perfusion defect on SPECT-MPI, were defined as secondary endpoints.

\section{Electrocardiogram (ECG) measurements}

The degree of myocardial reperfusion in this study was assessed by ECG ST-segment recovery, because it has strong power for predicting death, heart failure or shock up to 90 days after STEMI [37]. A standard 12-lead ECG was recorded at baseline and $\approx 30$ minutes after pPCI. All ECG records were magnified and ST-E was measured at the J point to the nearest $0.05 \mathrm{mV}$. The person performed ECG measurement was blinded to other clinical and laboratory data. In the current study, we used a simple ST-segment- recovery method of residual ST-E measured in the most affected lead on the post-PCI ECG, since this method was previously shown to perform as well as complex ones in predicting outcomes after primary PCI in STEMI [38].

\section{Transthoracic echocardiographic examination with the CFR evaluation}

CMF in this study was assessed by transthoracic echocardiography and CFR of the infarct, i.e. the left anterior descending coronary artery (LAD), since this method is noninvasive, reliable and validated for CMF assessment in post pPCI patients [39-41]. It was performed on the $2^{\text {nd }}$ day after pPCI using a commercially available ultrasound machine (Acuson Sequa C 256, Siemens, Medical Solutions, USA) and a 3V2C multifrequency transducer using second harmonic technology. Echocardiography included conventional resting $2 \mathrm{D}$ examination with measurements of LV end-diastolic and end-systolic volumes (LV EDV and LV ESV) and ejection fraction (EF) by Simpson's methods, and evaluation of LAD CFR as previously described [39-41]. In short, color Doppler detection of the LAD flow was obtained by a modified apical approach using a 4-MHz transducer, with Doppler mapping velocity range set between 16 to $24 \mathrm{~cm} / \mathrm{sec}$. The systolic and diastolic coronary flow velocity spectrum was obtained at baseline and during the peak of hyperemia induced by i.v. adenosine $(0.14 \mathrm{mg} / \mathrm{kg} / \mathrm{min}$ during 1 minute). CFR was calculated as the ratio of hyperemic to basal peak diastolic flow velocities. All studies were digitally recorded and stored for off-line analysis by two experienced examiners blinded to patient clinical data. The 
intraobserver and interobserver variability for CFR LAD measurements in our laboratory is $<10 \%$ [40].

\section{SPECT-MPI}

Gated single-photon emission computed tomography myocardial perfusion imaging (SPECT-MPI) with $99 \mathrm{~m}$-technetium metoxy-isobutile-isonitrile (99mTc-MIBI) was done 6 weeks after pPCI to define the final infarct size (percentage of myocardium with fixed perfusion abnormalities) by the person blinded to other clinical and laboratory data. $740 \mathrm{MBq}$ of $99 \mathrm{mTc}-\mathrm{MIBI}$ was injected 10-15 minutes after sublingual administration of $0.5 \mathrm{mg}$ nitroglycerin coinciding with the peak hemodynamic response. The acquisition was performed 45-60 minutes after the injection. Gated SPECT-MPI data were acquired in the supine position with a single head SPECT gamma camera (Siemens, e.cam) equipped with a high-resolution low energy collimator. Sixty-four projection images were recorded over a $180^{\circ}$ semicircular orbit extending from the $45^{\circ}$ right anterior oblique position to the $45^{\circ}$ left posterior oblique position, with matrix size $64 \times 64$, zoom 1.45 , and gating 8 frames per cardiac cycle. Using the e.soft commercial software, transaxial tomograms were generated from gated projection data, reconstructed with a filtered back-projected algorithm, and reoriented to obtain oblique-angle tomograms parallel to the long and short axes of the left ventricle. The reconstructed data were projected as myocardial tomographic slices in short-axis, vertical-long, and horizontal-long axis views. The 4D-MSPECT software was then used for semiquantitative evaluation of myocardial perfusion and function. The extent of myocardial perfusion abnormalities (\%) was expressed relative to the left ventricle, based on polar maps. A large infarction was defined as SPECT-MPI perfusion abnormality $>20 \%$.

\section{Statistical analysis}

Continuous variables were tested for normal distribution using the Kolmogorov-Smirnov test. Normally distributed continuous variables are expressed with mean $\pm S D$, and continuous variables that did not show a normal distribution are expressed as the median value and interquartile range (IQR: $25^{\text {th }}, 75^{\text {th }}$ percentile). CFR was analyzed both as continuous variable (with normal distribution) and as categorical, with values $\geq 2$ considered as normal. Worst residual ST-E was analyzed as categorical $(<1 \mathrm{~mm}$, 1 to $<2 \mathrm{~mm}$, and $\geq 2 \mathrm{~mm}$ ). SPECT-MPI perfusion defect was analyzed as a continuous variable (without normal distribution) and categorical ( $>20 \%$ and $\leq 20 \%$ ). Categorical data are shown as frequencies and percentages. For comparison between HOMA the positive vs. negative group student $\mathrm{t}$-test, the $\chi^{2}$ test and the independent-samples Mann-Whitney U test were used. To account for multiple testing, Bonferroni's correction was applied. Spearman's rank correlation coefficients were used to assess the relationships between HOMA and other variables. Univariate and multivariate (backward Wald) binary logistic regression analysis were used to evaluate the relationship between outcome variables (residual ST-E $\geq 2 \mathrm{~mm}$, CFR $<2$ and SPECT-MPI perfusion defect $>20 \%$ ) and potential determinants including the HOMA index. Results are expressed as the odd ratios (ORs) and their 95\% confidence intervals $(\mathrm{CI})$ per one standard deviation increment of each measure (facilitating comparisons of effect sizes for individual measures). The statistical analyses were performed using SPSS (SPSS version 20.0 Inc., Chicago). Statistical significance was defined as $\mathrm{p}<0.05$.

\section{Results}

A total of 108 non-diabetic consecutive patients with first anterior STEMI treated by pPCI were initially screened for the study during the period from November 2009 to June 2010. Out of 108 initially screened patients 3 patients died before they completed the study and 1 was excluded due to poor acoustic window. The final study population included 104 patients. The SPECT-MPI studies were done in the subgroup of 61 patients who agreed to be examined and were able to come for this examination 6 weeks after pPCI. The incidence of HOMA index positivity was similar to that in the entire study group.

The median age in the study population was 57 years (IQR: $48-66)$ and $71 \%$ were male. They were mainly non smokers (67\%), hypertensive (62\%), had hypercholesterolemia (46\%) and $65 \%$ had BMI $>25 \mathrm{~kg} / \mathrm{m}^{2}$. The median time from symptom onset to pPCI was $4 \mathrm{~h}$.

Patient's clinical and laboratory characteristics according to HOMA index positivity (i.e. IR) on day 2 and day 7 are listed in Tables 1, 2, 3 and 4.

In the whole study group the HOMA index increased from day 2 (median 1.94; IQR: 1.42-2.85) to day 7 (median 2.33; IQR: $1.60-3.61)(\mathrm{p}<0.001)$, mainly due to the significant increment in insulin concentration. It increased from a median value of 8.37 IU/L (IQR: 6.63-11.65) on day 2 to a median value of $9.83 \mathrm{IU} / \mathrm{L}$ (IQR: 7.72-15.77) on day 7 ( $\mathrm{p}<0.001$ ). Glycaemia was similar on day 2 (median 5.3; IQR 4.9-5.9 $\mathrm{mmol} / \mathrm{L}$ ) and day 7 (median 5.3; IQR: 4.9-5.8 $\mathrm{mmol} / \mathrm{L})(\mathrm{p}=\mathrm{ns})$. According to EGIR (European Group for Insulin Resistance) criteria, 57 out of 104 patients (55\%) had IR on the $2^{\text {nd }}$ day and 60 out of 104 patients $(58 \%)$ had IR on the $7^{\text {th }}$ day.

\section{Relationship between insulin resistance and coronary microcirculatory function}

CFR after pPCI was significantly lower in patients with IR based on the HOMA index both on the $2^{\text {nd }}$ (Table 5) and $7^{\text {th }}$ day (Table 6$)(\mathrm{p}=0.002$, for both). In HOMA index positive groups, both on day 2 and day 7 there 
Table 1 Patients' characteristics according to the $2^{\text {nd }}$ day HOMA positivity

\begin{tabular}{|c|c|c|c|c|}
\hline & & $2^{\text {nd }}$ day HOMA index positive & $2^{\text {nd }}$ day HOMA index negative & $\mathrm{p}$ value \\
\hline & $n,(\%)$ & $57 / 104(55)$ & $47 / 104(45)$ & \\
\hline Age & Median (IQR) & $59(50-68)$ & $54(48-64)$ & 0.150 \\
\hline Male & n (\%) & $38(66)$ & $36(77)$ & 0.266 \\
\hline BMI $\left(\mathrm{kg} / \mathrm{m}^{2}\right)$ & Median (IQR) & $25.2(23.9-28.4)$ & $25.9(23.6-26.7)$ & 0.809 \\
\hline Hypertension & n (\%) & $37(65)$ & $27(57)$ & 0.436 \\
\hline Hypercholesterolemia & n (\%) & $29(51)$ & $19(40)$ & 0.289 \\
\hline Smokers & n (\%) & $18(32)$ & $16(34)$ & 0.790 \\
\hline Symptom onset to pPCI (min) & Median (IQR) & $257(160-300)$ & $210(143-300)$ & 0.156 \\
\hline Killip class on admission 1/2/3 & n (\%) & $32 / 20 / 5(56 / 35 / 9)$ & $31 / 13 / 3(66 / 28 / 6)$ & 0.592 \\
\hline Heart rate (bpm) & Median (IQR) & $81(73-94)$ & $74(65-81)$ & $0.010^{a}$ \\
\hline \multicolumn{5}{|l|}{ Angiographic findings } \\
\hline Infarct related artery $L A D$ & n (\%) & $57(100)$ & $47(100)$ & ns \\
\hline Multi vessel disease & n (\%) & $22(39)$ & $16(34)$ & 0.631 \\
\hline Initial (pre-stenting) TIMI flow 0/1/2/3 & n (\%) & $46 / 8 / 1 / 2(80 / 14 / 2 / 4)$ & $38 / 2 / 5 / 2(81 / 4 / 11 / 4)$ & 0.106 \\
\hline Location of culprit lesion, proximal/mid/distal LAD & n (\%) & $24 / 33 / 0(42 / 58 / 0)$ & $27 / 20 / 0(57 / 43 / 0)$ & 0.119 \\
\hline Rentrop grade, 0/1/2-3 & n (\%) & $34 / 10 / 3(73 / 21 / 6)$ & $50 / 7 / 0(88 / 12 / 0)$ & 0.059 \\
\hline \multicolumn{5}{|l|}{ Procedural data } \\
\hline No of the implanted stents & Median (IQR) & $1(1-1)$ & $1(1-2)$ & 0.154 \\
\hline Bare metal stent & n (\%) & $45(79)$ & $35(75)$ & 0.589 \\
\hline Final minimal stent diameter (mm) & Median (IQR) & $2.9(2.7-3.0)$ & $2.8(2.7-3.0)$ & 0.910 \\
\hline \multicolumn{5}{|l|}{ Post-procedural data } \\
\hline Slow/no reflow after pPCl & n (\%) & $9(16)$ & $3(6)$ & 0.135 \\
\hline \multicolumn{5}{|l|}{ Echocardiography } \\
\hline LV EDV (ml) & Mean \pm SD & $112.5 \pm 37.9$ & $111.6 \pm 36.1$ & 0.903 \\
\hline LV ESV (ml) & Mean \pm SD & $58.9 \pm 28.4$ & $56.7 \pm 25.5$ & 0.684 \\
\hline LV EF (\%) & Mean \pm SD & $49.8 \pm 10.0$ & $50.2 \pm 10.5$ & 0.846 \\
\hline
\end{tabular}

$\mathrm{IR}$, interquartile range; $\mathrm{BMI}$, body mass index; $\mathrm{PPCl}$, primary percutaneous coronary intervention; bpm, beat per minute; LAD, left anterior descending artery; TIMI, Thrombolysis in Myocardial Infarction; LV left ventricle; EDV, end diastolic volume; ESV, end systolic volume; EF, ejection fraction; SD, standard deviation.

${ }^{a}$ On the basis of Bonferroni's correction, a p-value less than 0.025 indicates statistical significance.

were significantly more patients with impaired CMF (i.e. CFR $<2$ ).

CFR significantly correlated with both HOMA indices (for $2^{\text {nd }}$ day HOMA: $r=-0.386$ and for $7^{\text {th }}$ HOMA: $\mathrm{r}=-0.331, \mathrm{p}<0.001$ ) (Figure 1). CFR correlated also with $2^{\text {nd }}$ day glycaemia $(\mathrm{r}=-0.238, \mathrm{p}=0.015)$ and $2^{\text {nd }}$ day insulinemia $(\mathrm{r}=-0.297, \mathrm{p}=0.002)$. CFR did not correlate with HbA1c $(r=0.007, p=0.941)$, weakly correlated with glycaemia on admission $(r=-0.187, p=0.054)$ and did not correlate with insulinemia on admission $(\mathrm{r}=0.007, \mathrm{p}=0.946)$.

In multivariable model $2^{\text {nd }}$ day HOMA was an independent predictor of impaired CFR after adjustment for significant univariate predictors (heart rate, TnI peak, hsCRP), previously shown predictors of myocardial reperfusion (time from symptom onset to pPCI, glucose on admission, NT-proBNP) and potential cofounding variables for IR (age, gender and BMI), with OR of 5.98 (95\% CI 1.88-19.03, $\mathrm{p}=0.002)$.

\section{Relationship between insulin resistance and degree of} myocardial reperfusion

The residual ST-E $\geq 2 \mathrm{~mm}$ on post-procedural ECG was significantly more frequent among patients with IR compared to those without IR, both on day 2 (Table 5) and day 7 (Table 6).

The $2^{\text {nd }}$ day HOMA index remained independently associated with residual ST-E $\geq 2 \mathrm{~mm}$ in multivariable analysis adjusted for significant univariate ST-E predictors (BMI and age), potential confounding variables for IR (gender) and previously shown predictors of myocardial reperfusion after primary PCI (time from symptom onset to $\mathrm{pPCI}$, glycaemia on admission), with the OR of 11.70 (95\% CI 2.46-55.51, $\mathrm{p}=0.002)$.

Relationship between insulin resistance and final infarct size In 66 out of 104 patients SPECT-MPI was done to assess the final infarct size 6 weeks after pPCI. Patients 
Table 2 Patients' characteristics according to the $7^{\text {th }}$ day HOMA positivity

\begin{tabular}{|c|c|c|c|c|}
\hline & & $7^{\text {th }}$ day HOMA index positive & $7^{\text {th }}$ day HOMA index negative & $p$ \\
\hline & n (\%) & 60/104 (58) & $44 / 104(42)$ & \\
\hline Age & Median (IQR) & $60(49-67)$ & $51(45-62)$ & 0.117 \\
\hline Male & n (\%) & $42(70)$ & $32(73)$ & 0.762 \\
\hline BMI $\left(\mathrm{kg} / \mathrm{m}^{2}\right)$ & Median (IQR) & $25.8(25.0-28.7)$ & $24.7(22.1-26.6)$ & $0.010^{\mathrm{a}}$ \\
\hline Hypertension & n (\%) & $38(63)$ & $26(59)$ & 0.660 \\
\hline Hypercholesterolemia & n (\%) & $26(43)$ & $22(50)$ & 0.500 \\
\hline Smokers & n (\%) & $19(32)$ & $15(34)$ & 0.795 \\
\hline Symptom onset to $\mathrm{pPCl}$ (min) & Median (IQR) & $250(180-330)$ & $185(135-300)$ & $0.031^{\mathrm{a}}$ \\
\hline Killip class on admission 1/2/3/4 & n (\%) & $32 / 23 / 5(54 / 38 / 8)$ & $31 / 10 / 3(71 / 23 / 6$ & 0.197 \\
\hline Heart rate (bpm) & Median (IQR) & $80(68-92)$ & $78(65-85)$ & $0.010^{\mathrm{a}}$ \\
\hline \multicolumn{5}{|l|}{ Angiographic findings } \\
\hline Infarct related artery LAD & n (\%) & $60(100)$ & $44(100)$ & ns \\
\hline Multi vessel disease & n (\%) & $26(43)$ & $12(27)$ & 0.093 \\
\hline Initial (pre-stenting) TIMI flow 0/1/2/3 & n (\%) & $50 / 4 / 2 / 4(83 / 7 / 3 / 7)$ & $34 / 6 / 4 / 0(77 / 14 / 9 / 0)$ & 0.122 \\
\hline Location of culprit lesion (proximal/mid/distal LAD) & & 29/31/0 (48/52/0) & $22 / 22 / 0(50 / 50 / 0)$ & 0.867 \\
\hline Rentrop grade 0/1/2-3 & n (\%) & 45/11/4 (75/19/6) & $37 / 7 / 0(85 / 15 / 0)$ & 0.2193 \\
\hline \multicolumn{5}{|l|}{ Procedural data } \\
\hline No of the implanted stents & Median (IQR) & $1(1-2)$ & $1(1-2)$ & 0.863 \\
\hline Bare metal stent & n (\%) & $44(73)$ & $36(82)$ & 0.310 \\
\hline Final minimal stent diameter (mm) & Median (IQR) & $2.9(2.7-3.1)$ & $2.8(2.7-3.0)$ & 0.744 \\
\hline \multicolumn{5}{|l|}{ Post-procedural data } \\
\hline Slow/no reflow after $\mathrm{pPCl}$ & n (\%) & $10(17)$ & $2(5)$ & 0.056 \\
\hline \multicolumn{5}{|l|}{ Echocardiography } \\
\hline LV EDV (ml) & Mean \pm SD & $117.2 \pm 35.2$ & $105.1 \pm 38.4$ & 0.100 \\
\hline LV ESV (ml) & Mean \pm SD & $63.5 \pm 26.3$ & $50.4 \pm 26.4$ & $0.014^{\mathrm{a}}$ \\
\hline LV EF (\%) & Mean \pm SD & $47.4 \pm 8.4$ & $53.4 \pm 11.4$ & $0.003^{a}$ \\
\hline
\end{tabular}

$\mathrm{IQR}$, interquartile range; $\mathrm{BMI}$, body mass index; $\mathrm{PPCl}$, primary percutaneous coronary intervention; bpm, beat per minute; $\mathrm{LAD}$, left anterior descending artery; TIMI, Thrombolysis in Myocardial Infarction; LV left ventricle; EDV, end diastolic volume; ESV, end systolic volume; EF, ejection fraction; SD, standard deviation.

${ }^{a}$ On the basis of Bonferroni's correction, a p-value less than 0.025 indicates statistical significance.

with IR based on the $7^{\text {th }}$ day HOMA index positivity had a larger perfusion defect compared to patients without IR ( $\mathrm{p}=0.027)$, however the difference was of borderline statistical significance when Bonferroni's correction was applied (Table 6). SPECT-MPI perfusion defect correlated with $7^{\text {th }}$ day HOMA index $(\mathrm{r}=$ $0.331, \mathrm{p}=0.008)$, but not with the $2^{\text {nd }}$ day HOMA index.

In the multivariable model the $7^{\text {th }}$ day HOMA index was an independent predictor of a large infarction (i.e., perfusion defect $>20 \%$ ) after adjustment for significant univariate predictors (TnI peak, time form symptom onset to $\mathrm{pPCI}$ ), previously shown predictors of myocardial reperfusion (glucose level on admission) and potential cofounding variables for IR (age, gender and BMI) with OR of 11.37 (95\% CI 1.34-96.21, p = 0.026).
Correlations between HOMA indices with biochemical and clinical parameters

The HOMA index on day 2 correlated with the HOMA index on day $7(\mathrm{r}=0.406, \mathrm{p}<0.001)$. The second day HOMA index significantly correlated with heart rate $(r=0.354, p<0.001)$, peak values of hs-CRP $(r=0.205$, $\mathrm{p}=0.037)$, NT-proBNP $(\mathrm{r}=0.230, \mathrm{p}=0.02)$ and Tn $\mathrm{I}(\mathrm{r}=$ $0.258, \mathrm{p}=0.009)$. The seventh day HOMA index was significantly associated with heart rate $(r=0.205, p=0.02)$, left ventricular ejection fraction $(r=-0.241, p=0.02)$, BMI $(r=0.231, p=0.019)$ and peak values of hs-CRP $(r=0.290$, $\mathrm{p}=0.003)$, NT-proBNP $(\mathrm{r}=0.321, \mathrm{p}=0.001)$ and Tn $\mathrm{I}$ $(\mathrm{r}=0.235, \mathrm{p}=0.017)$.

\section{Discussion}

The present study analyzed IR in the acute phase of STEMI in non-diabetic patients treated by pPCI. First, 
Table 3 Patients' laboratory data according to the $2^{\text {nd }}$ day HOMA index positivity

\begin{tabular}{|c|c|c|c|}
\hline & $2^{\text {nd }}$ day HOMA index positive $(\mathrm{N}=57)$ & $2^{\text {nd }}$ day HOMA index negative $(\mathrm{N}=47)$ & $\mathrm{p}$ \\
\hline \multicolumn{4}{|l|}{ Glucose (mmol/L) } \\
\hline admission & $7.8(6.6-9.0)$ & $7.6(6.4-9.4)$ & 0.667 \\
\hline $2^{\text {nd }}$ day & $5.7(5.2-6.3)$ & $4.9(4.5-5.3)$ & $<0.001^{\mathrm{a}}$ \\
\hline $7^{\text {th }}$ day & $5.5(4.9-5.9)$ & $5.2(4.9-5.6)$ & 0.042 \\
\hline \multicolumn{4}{|l|}{ Insulin (IU/L) } \\
\hline admission & $18.82(8.55-23.77)$ & $11.29(7.24-17.00)$ & $0.009^{a}$ \\
\hline $2^{\text {nd }}$ day & $11.32(8.88-13.52)$ & $6.59(4.78-7.50)$ & $<0.001^{\mathrm{a}}$ \\
\hline $7^{\text {th }}$ day & $10.81(8.42-19.65)$ & $8.80(7.0-11.52)$ & $<0.001^{\mathrm{a}}$ \\
\hline \multicolumn{4}{|l|}{ HOMA index } \\
\hline $2^{\text {nd }}$ day & $2.76(2.21-3.42)$ & $1.34(1.04-1.69)$ & $<0.001^{\mathrm{a}}$ \\
\hline $7^{\text {th }}$ day & $2.75(1.93-4.17)$ & $2.04(1.45-2.92)$ & $<0.001^{\mathrm{a}}$ \\
\hline $\mathrm{HbA} 1 \mathrm{c}(\%)$ & $5.6(5.4-5.8)$ & $5.5(5.3-5.7)$ & 0.063 \\
\hline WBC count on admission $\left(\times 10^{9} / \mathrm{L}\right)$ & $12.7(9.7-16.2)$ & $12.6(9.9-13.4)$ & 0.739 \\
\hline hs-CRP (mg/L) & $52.6(19.9-123.7)$ & $50.0(22.3-108.8)$ & 0.615 \\
\hline $\operatorname{Tnl}(\mu \mathrm{g} / \mathrm{L})$ & $134.20(48.38-165.00)$ & $106.80(79.84-190.17)$ & 0.171 \\
\hline NT-proBNP (pg/mL) & $2165(1176-4693)$ & $2099(650-4133)$ & 0.227 \\
\hline Total-C (mmol/L) & 5. $22(4.40-6.03)$ & $4.82(4.53-5.68)$ & 0.724 \\
\hline $\mathrm{HDL}-\mathrm{C}(\mathrm{mmol} / \mathrm{L})$ & $1.08(0.92-1.21)$ & $1.16(0.99-1.35)$ & 0.825 \\
\hline LDL-C (mmol/L) & $3.20(2.65-3.80)$ & $3.16(2.91-3.69)$ & 0.666 \\
\hline Apo A1 (g/L) & $1.24(1.11-1.36)$ & $1.38(1.15-1.53)$ & $0.006^{\mathrm{a}}$ \\
\hline Apo B (g/L) & $1.00(0.86-1.17)$ & $0.98(0.85-1.11)$ & 0.418 \\
\hline $\mathrm{TG}(\mathrm{mmol} / \mathrm{L})$ & $1.60(1.22-2.17)$ & $1.45(1.20-1.74)$ & 0.138 \\
\hline Uric acid ( $\mu \mathrm{mol} / \mathrm{L})$ & $280(231-332)$ & $277(209-329)$ & 0.518 \\
\hline eGFR (mL/min per $\left.1.73 \mathrm{~m}^{2}\right)$ & $89.06 \pm 22.63$ & $85.24 \pm 23.05$ & 0.398 \\
\hline
\end{tabular}

Data are presented as median (interquartile range), except eGFR that is presented as mean \pm standard deviation.

${ }^{a}$ On the basis of Bonferroni's correction, a p-value less than 0.025 indicates statistical significance.

Abbreviations: HOMA Homeostatic Model Assessment, HbA1c hemoglobin A1c, WBC white blood cells, $h s$-CRP high sensitive C-reactive protein, Tnl troponin I, NTproBNP N-terminal pro-brain natriuretic peptide, Total-C Total cholesterol, HDL-C high-density lipoprotein cholesterol, $L D L-C$ low-density lipoprotein cholesterol, Apo apolipoprotein, TG triglycerides, eGFR estimated glomerular filtration rate, SD standard deviation.

it confirms that IR in the early post pPCI period is common even in non-diabetic patients and changeable. Second, IR was related to the degree of myocardial reperfusion and correlated well with the CMF after mechanical revascularization, independently of other variables. Third, IR at the end of the first week after pPCI was an independent predictor of the final infarct size.

IR in the acute phase of STEMI is predominately part of acute glycometabolic response to stress [22]. The term acute IR implies its presence during acute (early) phase of STEMI. Although we included only patients without diabetes mellitus, we cannot strictly exclude the presence of IR before and/or after the first STEMI week, since evaluation of IR status was not done before or after this period. Generally, in critically ill patients acute IR is related to more severe acute illness and warrants poor clinical outcome $[42,43]$. By traditional concept, acute IR is induced by acute stress, with a small possibility to be further directly involved in the development or aggravation of acute illness. However, recent studies [18-21] challenge this concept to a certain extent.

Few studies have analyzed time dependent changes of acute IR and/or insulin sensitivity and have related it to clinical outcomes [22,43]. Nishio et al. [22] performed serial HOMA index measurements among patients going to $\mathrm{PPCI}$ and identified those with transient IR, in whom HOMA index correlated with stress hormones and patients with persistent IR, in whom HOMA index during the 4 months follow-up correlated with leptin and contributed to stent restenosis. In the current study acute IR was present in $55 \%$ of patients on the $2^{\text {nd }}$ day and in $58 \%$ of patients on the $7^{\text {th }}$ day. The HOMA index slightly, but statistically significantly increased from day 2 to day 7 , mainly due to the increment in insulin concentration. Similar increment in insulinemia in the early post PCI period in non-diabetic patients was previously reported [44]. The potential mechanisms are not clear. Effects of prolonged cardiovascular (hemodynamic) stress and 
Table 4 Patients' laboratory data according to the $7^{\text {th }}$ day HOMA index positivity

\begin{tabular}{|c|c|c|c|}
\hline & $7^{\text {th }}$ day HOMA index positive $(\mathrm{N}=60)$ & $7^{\text {th }}$ day HOMA index negative $(\mathrm{N}=44)$ & $\mathbf{p}$ \\
\hline \multicolumn{4}{|l|}{ Glucose (mmol/L) } \\
\hline admission & $7.9(6.6-9.7)$ & $7.6(6.1-9.1)$ & 0.134 \\
\hline $2^{\text {nd }}$ day & $5.6(5.1-5.9)$ & $4.9(4.6-5.3)$ & $<0.001^{\mathrm{a}}$ \\
\hline $7^{\text {th }}$ day & $5.6(5.2-5.9)$ & $4.9(4.8-5.3)$ & $<0.001^{\mathrm{a}}$ \\
\hline \multicolumn{4}{|l|}{ Insulin (IU/L) } \\
\hline admission & $12.37(9.21-21.82)$ & $10.53(7.45-18.43)$ & 0.056 \\
\hline $2^{\text {nd }}$ day & $8.70(7.26-12.28)$ & $7.56(5.14-10.10)$ & $0.017^{\mathrm{a}}$ \\
\hline $7^{\text {th }}$ day & $14.52(10.69-20.15)$ & $7.28(6.06-8.33)$ & $<0.001^{\mathrm{a}}$ \\
\hline HOMA index & $5.5(5.4-5.8)$ & & \\
\hline $2^{\text {nd }}$ day & $2.27(1.76-2.98)$ & $1.55(1.09-2.28)$ & $0.001^{\mathrm{a}}$ \\
\hline $7^{\text {th }}$ day & $3.24(2.54-4.19)$ & $1.51(1.21-1.83)$ & $<0.001^{\mathrm{a}}$ \\
\hline $\mathrm{HbA1c}(\%)$ & $5.5(5.4-5.8)$ & $5.6(5.3-5.8)$ & 0.801 \\
\hline WBC count on admission $\left(\times 10^{9} / L\right)$ & $12.7(10.0-16.2)$ & $12.6(9.7-13.2)$ & 0.246 \\
\hline hs-CRP (mg/L) & $57.3(27.3-113.3)$ & $38.1(22.0-76.7)$ & 0.030 \\
\hline $\operatorname{Tnl}(\mu \mathrm{g} / \mathrm{L})$ & $135.86(85.11-182.00)$ & $78.36(59.04-148.63)$ & $0.019^{a}$ \\
\hline NT-proBNP (pg/mL) & $2777(1702-4693)$ & $1157(496-4150)$ & $0.010^{\mathrm{a}}$ \\
\hline Total-C (mmol/L) & $4.24(3.77-4.67)$ & $4.26(3.83-5.04)$ & 0.613 \\
\hline $\mathrm{HDL}-\mathrm{C}(\mathrm{mmol} / \mathrm{L})$ & $0.83(0.70-0.99)$ & $0.93(0.82-1.12)$ & $0.011^{a}$ \\
\hline LDL-C (mmol/L) & $2.67(2.39-3.09)$ & $2.70(2.21-3.47)$ & 0.795 \\
\hline Apo A1 (g/L) & $1.10(0.96-1.30)$ & $1.18(1.10-1.25)$ & $0.037^{\mathrm{a}}$ \\
\hline Apo B (g/L) & $0.85(0.75-0.94)$ & $0.90(0.79-0.94)$ & 0.481 \\
\hline TG $(\mathrm{mmol} / \mathrm{L})$ & $1.39(1.11-1.85)$ & $1.23(0.97-1.64)$ & 0.129 \\
\hline Uric acid ( $\mu \mathrm{mol} / \mathrm{L})$ & $273(223-310)$ & $279(237-329)$ & 0.703 \\
\hline eGFR $\left(\mathrm{mL} / \mathrm{min}\right.$ per $\left.1.73 \mathrm{~m}^{2}\right)$ & $89.09 \pm 25.23$ & $84.95 \pm 19.00$ & 0.342 \\
\hline
\end{tabular}

Data are presented as median (interquartile range), except eGFR that is presented as mean \pm standard deviation.

${ }^{a}$ On the basis of Bonferroni's correction, a p-value less than 0.025 indicates statistical significance.

Abbreviations: HOMA Homeostatic Model Assessment, HbA1c hemoglobin A1c, WBC white blood cells, hs-CRP high sensitive C-reactive protein, Tnl troponin I, NTproBNP N-terminal pro-brain natriuretic peptide, Total-C Total cholesterol, HDL-C high-density lipoprotein cholesterol, LDL-C low-density lipoprotein cholesterol, Apo apolipoprotein, TG triglycerides, eGFR estimated glomerular filtration rate, $S D$ standard deviation.

inflammation induced by STEMI could be the reasons [44]. In our study the $7^{\text {th }}$ day HOMA index correlated better than the $2^{\text {nd }}$ day HOMA index with the peak values of NT-proBNP and hs-CRP. Nutritional status might also influence the IR increment. In our study the majority of patients were on regular nutrition on the $7^{\text {th }}$ day as opposed to the $2^{\text {nd }}$ day, with a higher fat intake and potentially higher free fatty acids effects on the insulin sensitivity $[45,46]$. However, a comprehensive nutrition data analysis was not done. The effect of drugs should not be neglected, including those of thiazide diuretics, beta blockers and some statins [47-49], reported to have potential impact on insulin sensitivity. However, in the current study we could not find significant differences between HOMA positive and HOMA negative patients regarding the drug regime. None of the patients reached the glycaemic threshold of $11 \mathrm{mmol} / 1$ to get insulin.

One of the main findings in the current study is that acute IR was related to more impaired CMF after pPCI, independently of other potential covariates. CFR is a sensitive parameter of CMF. CMF after STEMI is important for the clinical outcome independently of epicardial flow [50]. Although the inverse relationship between HOMA index and CFR was described in different states [51-53], to the best of our knowledge the current study is the first to link acute IR assessed by the HOMA index and CFR in non-diabetic STEMI patients. Acute hyperglycemia per se predicted impaired epicardial flow before pPCI [54] and impaired CMF after pPCI in unselected, mixed diabetic and non-diabetic patients [55]. It is related to increased oxidative stress in STEMI, increases vascular cell apoptosis and induces acute endothelial dysfunction [56,24,57]. Insulin is under healthy condition coronary vasodilatator and in the dose-dependent manner increases myocardial blood flow [58,59]. However, these effects are abolished in chronic, obesity related IR [60,61]. Only one study evaluated acute insulinemia and coronary flow in acute coronary syndrome. In 60 patients admitted to the emergency 
Table 5 Outcome variables according to the $2^{\text {nd }}$ day HOMA index positivity

\begin{tabular}{llll}
\hline & $\begin{array}{l}2^{\text {nd }} \text { day HOMA } \\
\text { index positive }\end{array}$ & $\begin{array}{l}2^{\text {nd }} \text { day HOMA } \\
\text { index negative }\end{array}$ & p \\
\hline ECG $(n=104)$ & $(n=57)$ & $(n=47)$ & \\
Worst residual ST-E & & & $0.001^{\text {a }}$ \\
$<1 \mathrm{~mm}, \mathrm{n}(\%)$ & $9(16)$ & $18(38)$ & \\
$1-2 \mathrm{~mm}, \mathrm{n}(\%)$ & $6(10)$ & $11(24)$ & \\
$\geq 2 \mathrm{~mm}, \mathrm{n}(\%)$ & $42(74)$ & $18(38)$ & \\
Echocardiography $(n=104)$ & $(n=57)$ & $(n=47)$ & \\
CFR, mean \pm SD & $1.71 \pm 0.36$ & $1.93 \pm 0.37$ & $0.002^{\mathrm{a}}$ \\
CFR $<2, \mathrm{n}(\%)$ & $47(83)$ & $23(49)$ & $<0.001^{\mathrm{a}}$ \\
SPECT-MPI $(n=66)$ & $(n=36)$ & $(n=30)$ & \\
Perfusion defect, \%, (IQR) & $38(7-41)$ & $29(4-48)$ & 0.957 \\
\hline
\end{tabular}

HOMA, Homeostatic Model Assessment; ECG, electrocardiogram; ST-E, ST segment elevation; CFR, Coronary Flow Reserve; SD, standard deviation; SPECT-MPI, single-photon emission computed tomography myocardial perfusion image $\mathrm{IQR}$, interquartile range.

${ }^{a}$ On the basis of Bonferroni's correction, a p-value less than 0.025 indicates statistical significance.

department for suspected acute coronary syndrome acute hyperinsulinemia was present in half of them, and closely correlated with TIMI coronary flow score [31]. In the current study CFR better correlated to the HOMA index than to acute glycaemia and/or insulinemia and in the multivariable model including admission glycaemia, the HOMA index remained an independent CFR predictor. These data might suggest that acute IR as a phenomenon per se could be related to the development of CMF impairment after pPCI.

Table 6 Outcome variables according to the $7^{\text {th }}$ day HOMA index positivity

\begin{tabular}{|c|c|c|c|}
\hline & $\begin{array}{l}7^{\text {th }} \text { day HOMA } \\
\text { index positive }\end{array}$ & $\begin{array}{l}7^{\text {th }} \text { day HOMA } \\
\text { index negative }\end{array}$ & $p$ \\
\hline ECG $(n=104)$ & $(n=60)$ & $(n=44)$ & \\
\hline \multicolumn{3}{|l|}{ Worst residual ST-E } & $<0.001^{\mathrm{a}}$ \\
\hline$<1 \mathrm{~mm}, \mathrm{n}(\%)$ & $6(10)$ & $21(48)$ & \\
\hline $1-2$ mm, n (\%) & $13(22)$ & $3(7)$ & \\
\hline$\geq 2$ mm, n (\%) & $41(68)$ & $20(45)$ & \\
\hline Echocardiography $(n=104)$ & $(n=60)$ & $(n=44)$ & \\
\hline CFR, mean $\pm S D$ & $1.71 \pm 0.39$ & $1.95 \pm 10.33$ & $0.002^{a}$ \\
\hline CFR $<2, \mathrm{n}(\%)$ & $48(80)$ & $22(50)$ & $0.001^{\mathrm{a}}$ \\
\hline SPECT-MPI $(n=66)$ & $(n=37)$ & $(n=29)$ & \\
\hline $\begin{array}{l}\text { Perfusion defect, \%, } \\
\text { median (IQR) }\end{array}$ & $39(32-50)$ & $20(0-43)$ & 0.027 \\
\hline \multicolumn{4}{|c|}{$\begin{array}{l}\text { HOMA, Homeostatic Model Assessment; ECG, electrocardiogram; ST-E, ST segment } \\
\text { elevation; CFR, Coronary Flow Reserve; SD, standard deviation; SPECT-MPI, } \\
\text { single-photon emission computed tomography myocardial perfusion image; } \\
\text { IQR, interquartile range. } \\
\text { aOOn the basis of Bonferroni's correction, a p-value less than } 0.025 \text { indicates } \\
\text { statistical significance. }\end{array}$} \\
\hline
\end{tabular}

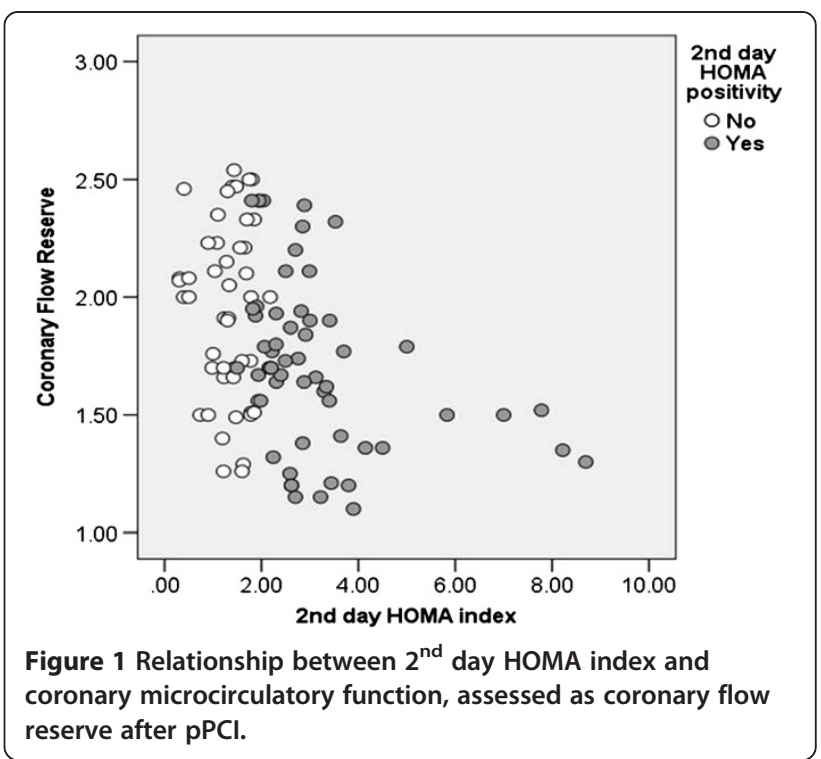

The relationship between acute IR and ST-E resolution was not previously evaluated. Acute hyperglycemia was related to limited ST-E recovery in mixed diabetic and non-diabetic STEMI population after thrombolytic therapy [62] and after pPCI [63]. Metabolic syndrome (chronic IR) was a predictor of ST-E resolution after pPCI [11]. In the current study in patients without diabetes, incomplete ST-E resolution was significantly more frequent among those with acute IR. However, only the $2^{\text {nd }}$ day HOMA index was independently associated with the residual ST-E.

The relationship between acute IR in non-diabetic STEMI patients and myocardial damage in terms of peak enzymes was previously reported $[18,19]$. In our study both HOMA indices correlated well with the peak TnI. However, only the $7^{\text {th }}$ day HOMA index was an independent predictor of the final infarct size on SPECT-MPI. It could be speculated that prolonged IR during acute phase is important. Furthermore, the $7^{\text {th }}$ day HOMA index might not only be a part of acute glycolmetabolic response to stress, but also part of chronic or prolonged intermittent IR that might influence formation of final infarct size in the following weeks after STEMI.

From the clinical standpoint, in the current study HOMA index on day 2 better correlated with myocardial reperfusion, both HOMA indices well correlated with the CMF, whereas HOMA index on day 7 predicted final infarct size. Both data might be clinically valuable: HOMA index on day 2 for the in-hospital course, HOMA index on day 7 for the long-term processes such as formation of the final infarct size. Although our data do not unambiguously demonstrate cause and effect relationship between acute IR and CMF, they strengthen the need for attention to be paid to IR during and after STEMI. Taking in mind that IR could be potentially modified, its regulation might 
become a therapeutic target both in acute STEMI and afterwards.

\section{Study limitations}

Study results should be interpreted with some limitations. First, our study is a single centre experience with a relatively small sample size. Second, CMF was measured by echocardiography without invasive or magnetic resonance imaging. However, this approach has been previously validated in our laboratory or elsewhere [39-41] and compared to positron emission tomography imaging [39]. Third, IR assessment was based on the HOMA index and EGIR classification, which was primarily defined for chronic states. Whether different cut-offs for acute IR should be used in the acute phase of myocardial infarction, as suggested by some authors [21], remains an open question. In the current study the "area at risk" was not determined by SPECT-MPI. However, there were no significant differences between patients with IR vs. without IR regarding the infarct related artery, the position of the culprit lesion and collateral circulation.

\section{Conclusion}

In conclusion, our results suggest that acute IR after pPCI in non-diabetic STEMI patients is related to impaired myocardial reperfusion, impaired CMF and potentially to a larger final infarct size.

\section{Abbreviations \\ IR: Insulin resistance; STEMI: ST segment elevation myocardial infarction; HOMA: Homeostatic model assessment; pPCl: Primary percutaneous coronary intervention; CMF: Coronary microcirculatory function; LAD: Left anterior descending artery; HbA1c: Hemoglobin A1c; CFR: Coronary flow reserve; LV: Left ventricle; Tnl: Troponin I; NT-proBNP: N-terminal pro-brain natriuretic peptide; hs-CRP: High-sensitive C-reactive protein; eGFR: Estimated glomerular filtration rate; TIMI: Thrombolysis in myocardial infarction; ST-E: ST segment elevation; SPECT-MPI: Single-photon emission computed tomography myocardial perfusion image; LV EDV: Left ventricular end diastolic volume; LV ESV: Left ventricular end systolic volume; LV EF: Left ventricular ejection fraction; IQR: Interquartile range; OR: Odd ratio; Cl: Confidence interval; WBC: White blood cells; HDL: High-density lipoprotein; LDL: Low-density lipoprotein; Apo: Apolipoprotein.}

\section{Competing interests}

The authors declare that they have no competing interest.

\section{Authors' contributions}

DT: conceived the study, participated in the design of the study, performed echocardiographic and CFR examinations, helped to perform statistic analysis and helped to write the manuscript. SS: carried out laboratory analysis and helped to write the manuscript. DSS: carried out SPECT-MPI analysis and helped to write the manuscript. MP: helped in ECG analysis. BB carried out cath lab work, angiographic analysis, and reviewed the manuscript. MB helped in echocardiographic examinations and cat lab work. JM participated in the design of the study, performed statistical analysis. DO performed cath lab work and angiographic analysis. BVT supervised echocardiographic examinations. MP performed echocardiographic examination. IN: performed echocardiographic examination. JS: participated in the design of the study. ADD: helped in CFR measurements. MT: helped in CFR measurements. ND: helped to carry out laboratory analysis. OP: performed echocardiographic examination and CFR measurements. OV: helped in ECG analysis. EN: helped in echocardiographic examination. JK: carried out cath lab work and angiographic analysis. AR: helped in coordination. MO: participated in the design of the study. All authors read and approved the final manuscript.

\section{Acknowledgement}

This study is part of the projects organized by Ministry of education and science, Republic of Serbia, No 145053, III41022 and ON 175086.

\section{Author details}

'Department of Cardiology, Clinical Centre of Serbia, UI. Koste Todorovica 8, 11000 Belgrade, Serbia. ${ }^{2}$ School of Medicine, University of Belgrade, Belgrade, Serbia. ${ }^{3}$ Center for Medical Biochemistry, Clinical Centre of Serbia, School of Pharmacy, University of Belgrade, Belgrade, Serbia. ${ }^{4}$ Department of Nuclear medicine, Clinical Centre of Serbia, Belgrade, Serbia. ${ }^{5}$ Institute of Medical Statistics and Informatics, School of Medicine, University of Belgrade, Belgrade, Serbia. ${ }^{6}$ Institute for Gerontology and Palliative Care, Belgrade, Serbia. ${ }^{7}$ Serbian Academy of Sciences and Arts, University of Belgrade, Belgrade, Serbia.

Received: 20 February 2014 Accepted: 2 April 2014 Published: 5 April 2014

\section{References}

1. Task Force on the management of ST-segment elevation acute myocardial infarction of the European Society of Cardiology (ESC): Guidelines for the management of acute myocardial infarction in patients presenting with ST-segment elevation. Eur Heart J 2012, 33(20):2569-2619.

2. Lerman A, Holmes DR, Herrmann J, Gersh BJ: Microcirculatory dysfunction in ST-elevation myocardial infarction: cause, consequence, or both? Eur Heart J 2007, 28(7):788-97.

3. Niccoli G, Burzotta F, Galiuto L, Crea F: Myocardial no-reflow in humans. J Am Coll Cardiol 2009, 54(4):281-292.

4. Robins SJ, Lyass A, Zachariah JP, Massaro JM, Vasan RS: Insulin resistance and the relationship of a dyslipidemia to coronary heart disease: the Framingham Heart Study. Arterioscler Thromb Vasc Biol 2011, 31:1208-1214.

5. Bonora E, Kiechl S, Willeit J, Oberhollenzer F, Egger G, Meigs JB, Bonadonna $\mathrm{RC}$, Muggeo M: Insulin resistance as estimated by homeostasis model assessment predicts incident symptomatic cardiovascular disease in Caucasian subjects from the general population: the Bruneck study. Diabetes Care 2007, 30:318-324

6. Arnold SV, Lipska K, Li Y, Goyal A, Maddox TM, McGuire DK, Spertus JA, Kosiborod M: The reliability and prognosis of in-hospital diagnosis of metabolic syndrome in the setting of acute myocardial infarction. $J$ Am Coll Cardiol 2013, 62(8):704-708.

7. Uchida Y, Ichimiya S, Ishii H, Kanashiro M, Watanabe J, Yoshikawa D, Takeshita K, Sakai S, Amano T, Matsubara T, Murohara T: Impact of metabolic syndrome on various aspects of microcirculation and major adverse cardiac events in patients with ST-segment elevation myocardial infarction. Circ J 2012, 76(8):1972-1979.

8. Tartan Z, Ozer N, Uyarel H, Akgul O, Gul M, Cetin M, Kasikcioglu H, Cam N: Metabolic syndrome is a predictor for an ECG sign of no-reflow after primary $\mathrm{PCl}$ in patients with acute ST-elevation myocardial infarction. Nutr Metab Cardiovasc Dis 2008, 18(6):441-447.

9. Wensley I, Salaveria K, Bulmer AC, Donner DG, du Toit EF: Myocardial structure, function and ischaemic tolerance in a rodent model of obesity with insulin resistance. Exp Physiol 2013, 98(11):1552-1564.

10. Bøhmer E, Seljeflot I, Arnesen H, Hoffmann P, Abdelnoor M, Halvorsen S: The association between metabolic syndrome and infarct size in patients with acute myocardial infarction. Scand J Clin Lab Invest 2010, 70(4):287-293.

11. Kranjcec D, Altabas $\vee$ : Metabolic syndrome influencing infarct size and heart failure in patients with acute coronary syndrome: does gender matter? Endocr J 2012, 59(12):1065-1076.

12. Clavijo LC, Pinto TL, Kuchulakanti PK, Torguson R, Chu WW, Satler LF, Kent KM, Suddath WO, Pichard AD, Waksman R: Metabolic syndrome in patients with acute myocardial infarction is associated with increased infarct size and in-hospital complications. Cardiovasc Revasc Med 2006, 7(1):7-11.

13. Reddy KJ, Singh M, Bangit JR, Batsell RR: The role of insulin resistance in the pathogenesis of atherosclerotic cardiovascular disease: an updated review. J Cardiovasc Med (Hagerstown) 2010, 11:633-647. 
14. Jeppesen J, Hansen TW, Rasmussen S, Ibsen H, Torp-Pedersen C, Madsbad S: Insulin resistance, the metabolic syndrome, and risk of incident cardiovascular disease: a population-based study. J Am Coll Cardiol 2007, 49(21):2112-2119.

15. Karrowni W, Li Y, Jones PG, Cresci S, Abdallah MS, Lanfear DE, Maddox TM, McGuire DK, Spertus JA, Horwitz PA: Insulin resistance is associated with significant clinical atherosclerosis in nondiabetic patients with acute myocardial infarction. Arterioscler Thromb Vasc Biol 2013, 33(9):2245-2251.

16. Cadeddu C, Nocco S, Piano D, Deidda M, Cossu E, Baroni MG, Mercuro G: Early impairment of contractility reserve in patients with insulin resistance in comparison with healthy subjects. Cardiovasc Diabetol 2013 12(1):66.

17. Uetani T, Amano T, Harada K, Kitagawa K, Kunimura A, Shimbo Y, Harada K, Yoshida T, Kato B, Kato M, Marui N, Nanki M, Hotta N, Ishii H, Matsubara T, Murohara T: Impact of insulin resistance on post-procedural myocardial injury and clinical outcomes in patients who underwent elective coronary interventions with drug-eluting stents. JACC Cardiovasc Interv 2012, 5(11):1159-1167.

18. Lazzeri C, Valente S, Chiostri M, Picariello C, Gensini GF: Correlates of acute insulin resistance in the early phase of non-diabetic ST-elevation myocardial infarction. Diab Vasc Dis Res 2011, 8(1):35-42.

19. Lazzeri C, Sori A, Chiostri M, Gensini GF, Valente S: Prognostic role of insulin resistance as assessed by homeostatic model assessment index in the acute phase of myocardial infarction in nondiabetic patients submitted to percutaneous coronary intervention. Eur J Anaesthesio/ 2009, 26(10):856-862.

20. Lazzeri C, Valente S, Chiostri M, Attanà P, Mattesini A, Gensini GF: Acute insulin resistance assessed by the homeostatic model assessment in acute coronary syndromes without previously known diabetes. Angiology 2013. [Epub ahead of print]. doi:10.1177/0003319713489018.

21. Sanjuan R, Blasco ML, Huerta R, Palacios L, Carratala A, Nunyez J, Sanchis J: Insulin resistance and short-term mortality in patients with acute myocardial infarction. Int J Cardiol 2014, 172(2):e269-e270.

22. Nishio K, Shigemitsu M, Kusuyama T, Fukui T, Kawamura K, Itoh S, Konno N, Katagiri T: Insulin resistance in nondiabetic patients with acute myocardial infarction. Cardiovasc Revasc Med 2006, 7(2):54-60.

23. Lazzeri C, Valente S, Chiostri M, Attanà P, Picariello C, Gensini GF: The glucose dysmetabolism in the acute phase of non-diabetic ST-elevation myocardial infarction: from insulin resistance to hyperglycemia. Acta Diabetol 2013, 50(3):293-300.

24. Zarich WS, Nesto RW: Implications and treatment of acute hyperglycemia in the setting of acute myocardial infarction. Circulation 2007, 115(18):e436-e439.

25. Meier JJ, Deifuss S, Klamann A, Launhardt V, Schmiegel WH, Nauck MA Plasma glucose at hospital admission and previous metabolic control determine myocardial infarct size and survival in patients with and without type 2 diabetes: the Langendreer Myocardial Infarction and Blood Glucose in Diabetic Patients Assessment (LAMBDA). Diabetes Care 2005, 28(10):2551-2553.

26. Ishihara M, Kojima S, Sakamoto T, Asada Y, Tei C, Kimura K, Miyazaki S, Sonoda M, Tsuchihashi K, Yamagishi M, Ikeda Y, Shirai M, Hiraoka H, Inoue T, Saito F, Ogawa H, Japanese Acute Coronary Syndrome Study Investigators: Acute hyperglycemia is associated with adverse outcome after acute myocardial infarction in the coronary intervention era. Am Heart J 2005, 150(4):814-820.

27. Cruz-Gonzalez I, Chia S, Raffel OC, Sanchez-Ledesma M, Senatore F, Wackers FJ, Nathan DM, Jang IK: Hyperglycemia on admission predicts larger infarct size in patients undergoing percutaneous coronary intervention for acute ST-elevation myocardial infarction. Diabetes Res Clin Pract 2010, 88(1):97-102.

28. Ishihara M, Inoue I, Kawagoe T, Shimatani Y, Kurisu S, Nishioka K, Umemura T, Nakamura S, Yoshida M: Impact of acute hyperglycemia on left ventricular function after reperfusion therapy in patients with a first anterior wall acute myocardial infarction. Am Heart J 2003, 146(4):674-678.

29. García RG, Rincón MY, Arenas WD, Silva SY, Reyes LM, Ruiz SL, Ramirez F, Camacho PA, Luengas C, Saaibi JF, Balestrini S, Morillo C, López-Jaramillo P: Hyperinsulinemia is a predictor of new cardiovascular events in Colombina patients with a first myocardial infarction. Int J Cardiol 2011, 148(1):85-90.
30. Kragelund C, Snorgaard O, Køber L, Bengtsson B, Ottesen M, Højberg S, Olesen C, Kjaergaard JJ, Carlsen J, Torp-Petersen C, TRACE Study Group: Hyperinsulinaemia is associated with increased long-term mortality following acute myocardial infarction in non-diabetic patients. Eur Heart J 2004, 25(21):1891-1897.

31. Panza-Nduli J, Coulic V, Willems D, Devriendt J, Gottignies P, Staroukine M, De Bels D: Influence of blood insulin measurement in acute coronary syndrome. Crit Pathw Cardiol 2011, 10(4):185-188.

32. Moura FA, Carvalho LS, Cintra RM, Martins NV, Figueiredo VN, Quinaglia E, Silva JC, Almeida OL, Coelho OR, Sposito AC: Validation of surrogate indexes of insulin sensitivity in acute phase of myocardial infarction based on euglycemic hyperinsulinemic clamp. Am J Physiol Endocrinol Metab 2014, 306(4):E399-E403.

33. American Diabetes Association: Diagnosis and classification of diabetes mellitus. Diabetes Care 2014, 37(Suppl.1):S81-S90.

34. Balkau B, Charles M, for European Group for the Study of Insulin Resistance (EGIR): Comment on the provisional report from the WHO consultation. Diabet Med 1999, 16:442-443.

35. Levey AS, Coresh J, Greene T, Stevens LA, Zhang YL, Hendriksen S, Kusek JW, Van Lente F, Chronic Kidney Disease Epidemiology Collaboration: Using standardized serum creatinine values in the modification of diet in renal disease study equation for estimating glomerular filtration rate. Ann Intern Med 2006, 145:247-254.

36. Rentrop KP, Cohen M, Blanke H, Phillips RA: Changes in collateral channel filling immediately after controlled coronary artery occlusion by an angioplasty balloon in human subjects. J Am Coll Cardiol 1985, 5(3):587-592.

37. Sheehan FH, Braunwald E, Canner P, Dodge HT, Gore J, Van Natta P, Passamani ER, Williams DO, Zaret B: The effect of intravenous thrombolytic therapy on left ventricular function: a report on tissue-type plasminogen activator and streptokinase from the Thrombolysis in Myocardial Infarction (TIMI Phase I) trial. Circulation 1987, 75(4):817-829.

38. Buller CE, Fu Y, Mahaffey KW, Todaro TG, Adams P, Westerhout CM, White $H D$, van 't Hof AW, Van de Werf FJ, Wagner GS, Granger CB, Armstrong PW: ST-segment recovery and outcome after primary percutaneous coronary intervention for ST-elevation myocardial infarction: insights from the Assessment of Pexelizumab in Acute Myocardial Infarction (APEX-AMI) trial. Circulation 2008, 118:1335-1346.

39. Saraste M, Koskenvuo J, Knuuti J, Toikka J, Laine H, Niemi P, Sakuma H, Hartiala J: Coronary flow reserve: measurement with transthoracic Doppler echocardiography is reproducible and comparable with positron emission tomography. Clin Physiol 2001, 21(1):114-122.

40. Djordjevic-Dikic A, Beleslin B, Stepanovic J, Giga V, Tesic M, Dobric M, Stojkovic S, Nedeljkovic M, Vukcevic V, Dikic N, Petrasinovic Z, Nedeljkovic I, Tomasevic M, Vujisic-Tesic B, Ostojic M: Prediction of myocardial functional recovery by noninvasive evaluation of basal and hyperemic coronary flow in patients with previous myocardial infarction. J Am Soc Echocardiogr 2011, 24(5):573-581.

41. Rigo F, Varga Z, Di Pede F, Grassi G, Turiano G, Zuin G, Coli U, Raviele A, Picano E: Early assessment of coronary flow reserve by transthoracic Doppler echocardiography predicts late remodeling in reperfused anterior myocardial infarction. J Am Soc Echocardiogr 2004, 17(7):750-755.

42. Li L, Messina JL: Acute insulin resistance following injury. Trends Endocrinol Metab 2009, 20(9):429-435.

43. Pretty CG, Le Compte AJ, Chase JG, Shaw GM, Preiser JC, Penning S, Desaive T: Variability of insulin sensitivity during the first 4 days of critical illness: implications for tight glycemic control. Ann Intensive Care 2012, 2(1):17.

44. Gruzdeva O, Uchasova E, Dyleva Y, Belik E, Shurygina E, Barbarash O: Insulin resistance and inflammation markers in myocardial infarction. $J$ Inflamm Res 2013, 6:83-90.

45. Xiao C, Giacca A, Carpentier A, Lewis GF: Differential effects of monounsaturated, polyunsaturated and saturated fat ingestion on glucose-stimulated insulin secretion, sensitivity and clearance in overweight and obese, non-diabetic humans. Diabetologia 2006, 49:1371-1379.

46. Wolpert HA, Atakov-Castillo A, Smith SA, Steil GM: Implications for carbohydrate-based bolus dose calculation and intensive diabetes management. Diabetes Care 2013, 36(4):810-816.

47. Elliott WJ, Meyer PM: Incident diabetes in clinical trials of antihypertensive drugs: a network meta-analysis. Lancet 2007, 369:201-207.

48. Sattar N, Preiss D, Murray HM, Welsh P, Buckley BM, de Craen AJ, Seshasai SR, McMurray JJ, Freeman DJ, Jukema JW, Macfarlane PW, Packard CJ, Stott DJ, Westendorp RG, Shepherd J, Davis BR, Pressel SL, Marchioli R, Marfisi RM, Maggioni AP, Tavazzi L, Tognoni G, Kjekshus J, Pedersen TR, Cook TJ, Gotto 
AM, Clearfield MB, Downs JR, Nakamura H, Ohashi Y, et al: Statins and risk of incident diabetes: a collaborative meta-analysis of randomised statin trials. Lancet 2010, 375(9716):735-742.

49. Preiss D, Seshasai SR, Welsh P, Murphy SA, Ho JE, Waters DD, DeMicco DA, Barter P, Cannon CP, Sabatine MS, Braunwald E, Kastelein JJ, de Lemos JA, Blazing MA, Pedersen TR, Tikkanen MJ, Sattar N, Ray KK: Risk of incident diabetes with intensive-dose compared with moderate-dose statin therapy: a meta-analysis. JAMA 2011, 305(24):2556-2564

50. Yong AS, Fearon WF: Coronary microvascular dysfunction after ST-segment-elevation myocardial infarction: local or global phenomenon? Circ Cardiovasc Interv 2013, 6(3):201-203.

51. Eroglu S, Sade LE, Bozbas H, Haberal A, Ozbicer S, Demir O, Muderrisoglu H: Association of serum adiponectin levels and coronary flow reserve in women with normal coronary angiography. Eur J Cardiovasc Prev Rehabil 2009, 16(3):290-296.

52. Kondo I, Mizushige K, Hirao K, Nozaki S, Tsuji T, Masugata H, Kohno M, Matsuo H: Ultrasonographic assessment of coronary flow reserve and abdominal fat in obesity. Ultrasound Med Biol 2001, 27(9):1199-1205.

53. Snoer M, Monk-Hansen T, Olsen RH, Pedersen LR, Simonsen L, Rasmusen $H$, Dela F, Prescott E: Insulin resistance and exercise tolerance in heart failure patients: linkage to coronary flow reserve and peripheral vascular function. Cardiovasc Diabetol 2012, 11:97.

54. Timmer J, Ottervanger J, de Boer M, Dambrink JE, Hoorntje JCA, Gosselink ATM, Suryapranata H, Zijlstra F, Van't Hof AWJ, for the Zwolle Myocardial Infarction Study Group: Hyperglycemia is an important predictor of impaired coronary flow before reperfusion therapy in ST-segment elevation myocardial infarction. J Am Coll Cardiol 2005, 45(7):999-1002.

55. Iwakura K, Ito H, Ikushima M, Kawano S, Okamura A, Asano K, Kuroda T, Tanaka K, Masuyama T, Hori M, Fuji K: Association between hyperglycemia and the no-reflow phenomenon in patients with acute myocardial infarction. J Am Coll Cardiol 2003, 41(1):1-7.

56. Monnier L, Mas E, Ginet C, Michel F, Willon L, Cristol JP, Colette C: Activation of oxidative stress by acute glucose fluctuations compared with sustained chronic hyperglycemia in patients with type 2 diabetes. JAMA 2006, 295:1681-1687.

57. Chang J, Zhang G, Zhang L, Hou YP, Liu XL, Zhang L: High admission glucose levels increase Fas apoptosis and mortality in patients with acute ST-elevation myocardial infarction: a prospective cohort study. Cardiovasc Diabetol 2013, 12(1):171.

58. Sundell J, Nuutila P, Laine H, Luotolahti M, Kalliokoski K, Raitakari O, Knuuti J: Dose-dependent vasodilating effects of insulin on adenosine-stimulated myocardial blood flow. Diabetes 2002, 51(4):1125-1130.

59. Laine H, Nuutila P, Luotolahti M, Meyer C, Elomaa T, Koskinen P, Rönnemaa $T$, Knuuti J: Insulin-induced increment of coronary flow reserve is not abolished by dexamethasone in healthy young men. $J$ Clin Endocrinol Metab 2000, 85(5):1868-1873.

60. Rocchini AP, Wilson RF, Marker P, Cervenka T: Metabolic and hemodynamic effects of a graded intracoronary insulin infusion in normal and fat anesthetized dogs: a preliminary study. Hypertension 1996, 27(3):354-359

61. Sundell J, Laine H, Luotolahti M, Kalliokoski K, Raitakari O, Nuutila P, Knuuti J: Obesity affects myocardial vasoreactivity and coronary flow response to insulin. Obes Res 2002, 10(7):617-624.

62. L'Huillier I, Zeller M, Mock L, Beer JC, Laurent Y, Sicard P, Vincent-Martin M, Lorgis L, Makki H, Wolf JE, Freysz M, Cottin Y: Relation of hyperglycemia to ST-segment resolution after reperfusion for acute myocardial infarction (from Observatoire des Infarctus de Côte-d'Or Survey [RICO]). Am J Cardiol 2006, 98(2):167-171.

63. Chi HJ, Zhang DP, Xu Y, Yang ZS, Wang LF, Cui L, Yang XC: Relation of hyperglycemia to ST-segment resolution after primary percutaneous coronary intervention for acute myocardial infarction. Chin Med J (Engl) 2007, 120(21):1874-1877.

doi:10.1186/1475-2840-13-73

Cite this article as: Trifunovic et al: Acute insulin resistance in

ST-segment elevation myocardial infarction in non-diabetic patients is associated with incomplete myocardial reperfusion and impaired coronary microcirculatory function. Cardiovascular Diabetology 2014 13:73. 